\title{
Analisis Korelasi Pre Eklampsia Dalam Kehamilan Dengan Kejadian Asfiksia Neonatorum
}

\section{Analysis Of Pre Eclampsia Correlation In Pregnancy With The Incidence Of Asphyxia Neonatorum}

Nurul Auliya Kamila ${ }^{1}$, Siti Wathaniah²

1,2Program Studi DIII Kebidanan Fakultas Ilmu Kesehatan Universitas Nahdlatul Wathan Mataram

Email : mila_yk2007@yahoo.com

I N F O A R T I K E L

Sejarah artikel:

Menerima 27 April 2021

Revisi 2 Agustus 2021

Diterima 3 Agustus 2021

Online 10 Oktober 2021

Kata kunci:

Pre Eklampsia, Kejadian Asfiksia Neonatorum

Keywords:

Pre eclampsia, Asphyxia neonatorum

\begin{abstract}
ABSTRAK
Asfiksia neonatorum merupakan kegagalan bayi baru lahir untuk bernapas secara spontan dan teratur sehingga menimbulkan gangguan lebih lanjut. Timbulnya asfiksia pada bayi dengan ibu pre eklampsi disebabkan tekanan darah yang tinggi menyebabkan berkurangnya kiriman darah ke plasenta, ini akan mengurangi suplai oksigen dan makanan bagi bayi. Akibatnya, perkembangan bayi menjadi lambat, dan terjadi hipoksia intrauterin. Tujuan penelitian ini adalah untuk mengetahui Korelasi Pre Eklampsia dalam kehamilan dengan Kejadian Asfiksia Neonatorum di Ruang NICU RSUD Kota Mataram NTB Tahun 2020. Metode penelitian yang digunakan dalam penelitian ini adalah korelasional analitik dengan rancangan Case Control dengan pendekatan waktu Retrosfektif. Populasinya adalah data semua ibu bersalin yang ada di Ruang NICU RSUD Kota Mataram tahun 2020 sebanyak 1.098 orang. Teknik pengambilan sampel yang digunakan adalah sistematik random sampling sehingga jumlah sampel yang diperoleh sebanyak 124 sampel. Alat bantu yang digunakan adalah rekam medik. Analisa statistik yang digunakan adalah uji chi square. Hasil penelitian menunjukkan bahwa dari 124 sampel yang diteliti bahwa bayi asfiksia neonatorum pada ibu yang mengalami pre eklampsia adalah $39(62,9 \%)$ dibandingkan pada ibu yang tidak preeklampsia adalah $23(37,1 \%$ ). Hasil nilai probability value ( $\mathrm{p}$ value) $=0,000<\alpha 0,05$, dengan sendirinya Ho ditolak yang artinya ada korelasi pre eklampsi dengan asfiksia bayi baru lahir di RSUD Kota Mataram. Disarankan kepada tenaga kesehatan yang ada di RSUD Kota Mataram agar semakin meningkatkan mutu pelayanan kesehatan kepada masyarakat khususnya ibu hamil untuk tetap memeriksakan kesehatannya di tempat pelayanan kesehatan agar resiko terjadinya pre eklampsia dapat dicegah.
\end{abstract}

\section{ABSTRACT}

Asphyxia neonatorum is the failure of the newborn to breathe spontaneously and regularly, causing further disturbances. The onset of asphyxia in infants with preeclamptic mothers is due to high blood pressure causing reduced blood delivery to the placenta, this will reduce the supply of oxygen and food for the baby. As a result, the baby's development is slow, and intrauterine hypoxia occurs. The purpose of this study was to determine the correlation between pre-eclampsia in pregnancy and the incidence of asphyxia neonatorum in the NICU Room of the Mataram City Hospital, NTB in 2020. The research method used in this study was analytical correlational with a case control design with a retrospective time approach. The population is the data of all women giving birth in the NICU Room of Mataram City Hospital in 2020 as many as 1,098 people. The sampling technique used was systematic random sampling so that the number of samples obtained was 124 samples. The tools used are medical records. The statistical analysis used was the chi square test. The results showed that of the 124 samples studied, the neonatal asphyxia infants in mothers with pre-eclampsia were 39 
$(62.9 \%)$ compared to $23(37.1 \%)$ non-preeclamptic mothers, the results of the probability value $(p$ value $)=0.000<\alpha 0.05$, by itself Ho is rejected, which means that there is a relationship between pre-eclampsia and newborn asphyxia at the Mataram City Hospital. So it can be concluded that, mothers who experience preeclampsia tend to have neonatal asphyxia. It is recommended that health workers at the Mataram City Hospital to further improve the quality of health services to the community, especially mothers giving birth, to keep their health checked at the health service place so that the risk of pre-eclampsia can be prevented.

\section{PENDAHULUAN}

Angka kematian ibu (AKI) dan angka kematian bayi merupakan salah satu indikator dalam menentukan derajat kesehatan masyarakat. World Health Organization (WHO) memperkirakan di dunia setiap menit perempuan meninggal karena komplikasi yang terkait dengan kehamilan dan persalinan, dengan kata lain 1.400 perempuan meninggal setiap harinya atau diperkirakan terjadinya 500.000 kematian ibu melahirkan diseluruh dunia setiap tahunnya, 99\% diantaranya terjadi di negara berkembang. (Achadi, 2019)

Selama dua dekade terakhir telah terjadi penurunan yang signifikan pada angka kematian bayi di Indonesia, meskipun demikian angka kematian bayi di Indonesia masih tergolong tinggi jika dibandingkan dengan negara-negara ASEAN lainnya. Penurunan angka kematian bayi di Indonesia juga belum mencapai target MDGs 2015 (target MDGs 2015 untuk AKB adalah 23, sedangkan AKB hasil SDKI 2017 adalah 24. (Indradewi et al., 2019)

Data dari Dinas Kesehatan Kota Mataram 2007 Angka Kematian Bayi (AKB) sebesar 72 per 1.000 kelahiran hidup dan tahun 2012 Angka Kematian Bayi (AKB) sebesar 57 per 1.000 kelahiran hidup, angka kematian bayi ini mengalami penurunan sebesar 15 per 1.000 kelahiran hidup. Angka Kematian Bayi (AKB) disebabkan oleh BBLR (34\%), asfiksia (24\%), infeksi (23\%), prematur (11\%), dan lain-lain ( $8 \%$ ) (Profil Kesehatan Kota Mataram, 2018)

Asfiksia neonatorum merupakan kegagalan bayi baru lahir untuk bernapas secara spontan dan teratur sehingga menimbulkan gangguan lebih lanjut, yang ditandai dengan hipoksemia (penurunan paCO2), hiperkarbia (peningkatan paCO2), dan asidosis/penurunan $\mathrm{pH} 7$ yang mempengaruhi seluruh metabolisme tubuhnya. (Mochtar, 2008) Keadaan depresi pernapasan yang dimaksud adalah keadaan asfiksia yang terjadi kesulitan untuk mempertahankan pernapasan normal yang menyebabkan gangguan tonus otot. (Manuaba, 2019)

Beberapa faktor yang menjadi penyebab terjadinya asfiksia pada bayi baru lahir, diantaranya adalah faktor dari ibu yaitu, hipoksia pada ibu, usia ibu kurang dari 20 tahun atau lebih dari 35 tahun, paritas jumlah anak yang dilahirkan, dan penyakit yang diderita ibu seperti hipertensi dan hipotensi. Kemudian faktor plasenta yaitu, plasenta previa, dan solusio plasenta. Faktor dari janin yaitu, prematur, kehamilan ganda, gangguan tali pusat. Dan faktor dari persalinan yaitu, persalinan buatan/persalinan anjuran, dan partus lama yaitu persalinan lebih dari 18 jam. (Fanny, 2015)

Komplikasi pre eklampsia pada janin adalah janin yang dikandung ibu hamil pre eklampsia akan hidup dalam rahim dengan nutrisi dan oksigen di bawah normal. Keadaan ini bisa terjadi karena pembuluh darah yang menyalurkan darah ke plasenta menyempit, karena buruknya nutrisi pertumbuhan janin akan terhambat sehingga akan terjadi bayi dengan berat lahir rendah. Bisa juga janin dilahirkan kurang bulan (prematuritas). Hipertensi Dalam Kehamilan adalah salah satu trias penyebab utama kematian ibu disamping perdarahan dan infeksi. Di Indonesia, pre eklampsi dan eklampsi merupakan penyebab kematian ibu yang berkisar 15\% - 25\%. (Meliati, 2013). Komplikasi 
yang ditimbulkan dari pre eklampsi adalah morbiditas tinggi yang diantaranya menyebabkan asfiksia, tumbuh kembang tak normal serta mortalitas yang diantaranya menyebabkan asfiksia berat, perdarahan intraventrikel, trauma persalinan, dan infeksi organ vital. (Wiknjosastro, 2009)

Diagnosia bayi baru lahir dengan asfiksia neonatorum dapat dilakukan dengan menetapkan nilai Apprearance, Pulse, Grimace, Activity, Respiration, (APGAR) penilaian asfiksia neonatorum menggunakan skor Apgar ditentukan sehingga penatalaksanaan pada bayi dapat disesuaikan dengan keadaan bayi. Sebagian kasus asfiksia pada bayi baru lahir merupakan kelanjutan dari asfiksia intrauterin, karena diagnose asfiksia penting dalam merencanakan resusitasi yang akan dilakukan.

Berdasarkan studi pendahuluan yang telah di lakukan di di Ruang NICU RSUD Kota Mataram pada tanggal 20 Juni 2020 menunjukkan bahwa pada tahun 2018 terdapat sebanyak 1.502 ibu bersalin, yang mengalami pre eklampsia sebanyak 264 orang $(17,57 \%)$, dan jumlah bayi yang mengalami asfiksia neonatorum sebanyak 318 orang (21,17\%) sedangkan pada tahun 2019 sebanyak $1.098 \mathrm{ibu}$ bersalin, yang mengalami pre eklampsia sebanyak 383 orang $(24,41 \%)$ dan jumlah bayi yang mengalami asfiksia neonatorum sebanyak 428 orang $(26,16 \%)$. Dari data tersebut dapat dilihat bahwa ibu yang mengalami pre eklampsia dan asfiksia neonatorum dari tahun 2018 sampai dengan tahun 2019 mengalami peningkatan (RSUD Kota Mataram, 2020).

Berdasarkan uraian latar belakang di atas, maka peneliti tertarik untuk melakukan penelitian tentang : "Analisis Korelasi Pre Eklampsia Dalam Kehamilan Dengan Kejadian Asfiksia Neonatorum Di RSUD Kota Mataram NTB".

\section{METODE PENELITIAN}

Penelitian ini penelitian korelasional analitik, rancangan penelitian case control yaitu suatu penelitian (survei) analitik yang menyangkut bagaimana faktor resiko dipelajari dengan pendekatan waktu retrospektif. Subjek penelitian yaitu semua data ibu bersalin dan data bayi yang ada di Ruang bersalin dan Nicu RSUD Kota Mataram tahun 2019 sebanyak 1.098 orang. Pengambilan sampel menggunakan teknik sistematik random sampling yaitu dengan cara memberikan nomor urut pada populasi setelah itu mencari interval (K) dengan membagi jumlah populasi dengan sampel. Cara mengambilnya, yang pertama dengan memberikan nomor urut pada semua populasi kemudian melakukan pengundian secara acak, keluar nomor 2 maka dihitung dengan kelipatan 2 yaitu 2, 19, 36, 53, 70 dan seterusnya sampai mendapatkan sampel sebanyak 124 sampel. Analisis deskriptif (Univariat) dan analisa bivariate yaitu analisis bivariat dilakukan terhadap dua variabel yang diduga berhubungan atau berkorelasi. Meliputi satu variabel independen (kejadian pre eklampsia) dan variabel dependen (asfiksia neonatorum). Kemudian untuk analisis hubungan menggunakan uji chi square. Pengolahan data melalui editing, coding, scoring, tabulating

\section{DISKUS}

a. Pada penelitian ini, kejadian asfiksia neonatorum pada bayi dikelompokkan menjadi 2 kategori yaitu : asfiksia dan tidak asfiksia. Untuk lebih jelasnya dapat dilihat pada tabel 5.1 berikut 
Tabel 5.1 Distribusi Frekuensi Sampel Berdasarkan Kejadian Asfiksia Neonatorum di RSUD Kota Mataram Tahun 2020

\begin{tabular}{clcc}
\hline No & Kejadian Asfiksia & $\mathbf{n}$ & \% \\
\hline $\mathbf{1}$ & Asfiksia Neonatorum & 62 & 50 \\
$\mathbf{2}$ & Tidak Asfiksia Neonatorum & 62 & 50 \\
\hline & Jumlah & 124 & 100
\end{tabular}

Sumber : (Data primer terolah Tahun 2020)

Berdasarkan tabel 5.1 di atas dapat dilihat bahwa dari 124 responden, sebanyak 62 bayi (50\%) mengalami asfiksia (Kasus) dan 62 bayi (50\%) tidak mengalami asfiksia (Kontrol).

Bayi yang mengalami asfiksia neonatorum di Ruang NICU RSUD Kota Mataram disebabkan oleh beberapa faktor yaitu : faktor ibu yaitu usia dan paritas ibu, faktor janin seperti prematur, dan janin kembar, faktor plasenta dan faktor persalinan seperti persalinan lama dan persalinan buatan. Proses terjadinya asfiksia berawal dari reaksi bayi terhadap kesulitan selama masa transisi normal. Bayi baru lahir akan melakukan usaha untuk menghirup udara ke dalam paruparunya yang mengakibatkan cairan paru keluar dari alveoli ke jaringan insterstitial di paru sehingga oksigen dapat dihantarkan ke arteriol pulmonal dan menyebabkan arteriol berelaksasi. Jika keadaan ini terganggu maka arteriol pulmonal akan tetap konstriksi, alveoli tetap terisi cairan dan pembuluh darah arteri sistemik tidak mendapat oksigen (Maryunani, 2010)

Hal ini diperkuat oleh teori yang menyatakan bahwa asfiksia dapat dipengaruhi oleh beberapa faktor yaitu faktor langsung dan tidak langsung. Yang termasuk dalam faktor langsung adalah faktor ibu, faktor tali pusat dan faktor bayi. Sedangkan faktor tidak langsung yang mempengaruhi asfiksia diantaranya adalah status ekonomi keluarga, pendidikan ibu, perawatan masa hamil, paritas, jarak kelahiran, faktor 3T, dan tempat pelayanan persalinan. (Maryunani, 2010)

b. Pada penelitian ini, kejadian pre eklampsia pada ibu dikelompokkan menjadi 2 kategori yaitu : Pre eklampsia dan tidak pre eklampsia. Untuk lebih jelasnya dapat dilihat pada tabel 5.2 berikut:

Tabel 5.2 Distribusi Frekuensi Sampel Berdasarkan Kejadian Pre eklampsia di RSUD Kota Mataram Tahun 2020

\begin{tabular}{rlcc}
\hline No & Kejadian Pre Eklampsia & n & \% \\
\hline $\mathbf{1}$ & Pre Eklampsia & 49 & 39,5 \\
$\mathbf{2}$ & Tidak Pre Eklampsia & 75 & 60,5 \\
\hline & Jumlah & 124 & 100
\end{tabular}

\section{Sumber: (Data primer terolah Tahun 2020)}

Berdasarkan tabel di atas dapat dilihat bahwa dari 124 responden, sebanyak 49 orang (39.5\%) mengalami pre eklampsi sedangkan 75 orang $(60.5 \%)$ tidak mengalami pre eklampsi. Pre eklampsi ialah penyakit dengan tanda-tanda hipertensi, edema, dan proteinuria yang timbul karena kehamilan. Penyakit ini umumnya terjadi dalam triwulan ke-3 kehamilan, tetapi dapat terjadi sebelumnya. Pre eklampsi sangat berbahaya bagi ibu yang sedang hamil karena 
dapat mengganggu kesehatan ibu dan janin seperti yang dikemukan oleh Prawirohardjo (2013) bahwa tekanan darah yang tinggi menyebabkan berkurangnya kiriman darah ke plasenta. Sudah pasti ini akan mengurangi suplai oksigen dan makanan bagi bayi. Akibatnya, bayi mengalami hipoksia dan perkembangan bayi pun jadi lambat, dan memicu terjadinya persalinan dini dan asfiksia. Lebih fatal lagi, penyakit ini bisa menyebabkan lepasnya jaringan plasenta secara tiba-tiba dari uterus sebelum waktunya. Pada kasus tekanan darah tinggi kronis atau gestational hypertention pada ibu hamil yang serius, bisa berkembang menjadi penyakit pre eklampsi atau keracunan kehamilan. Masih adanya ibu hamil yang menderita pre eklampsi disebabkan karena beberapa faktor pemicu seperti umur ibu yang beresiko terhadap kejadian pre eklampsi karena berdasarkan data yang peneliti peroleh, ibu yang

Tabel 5.3 Hbungan Persalinan Preterm dengan Kejadian Asfiksia Di Ruang NICU RSUD Kota Mataram tahun 2020

\begin{tabular}{|c|c|c|c|c|c|c|c|}
\hline \multirow[t]{2}{*}{ Pre Eklampsia } & \multicolumn{4}{|c|}{ Kejadian Asfiksia Neonatorum } & \multicolumn{2}{|c|}{ Total } & \multirow{2}{*}{$\begin{array}{l}\text { P value } \\
0,000\end{array}$} \\
\hline & Ya & & & & & & \\
\hline & $\mathrm{n}$ & $\%$ & $\mathrm{n}$ & $\%$ & $\mathrm{~N}$ & $\%$ & \\
\hline Ya & 39 & 62,9 & 10 & 16,1 & 49 & 39,5 & \\
\hline Tidak & 23 & 37,1 & 52 & 83,9 & 75 & 60,5 & \\
\hline Jumlah & 62 & 100 & 62 & 100 & 124 & 100 & \\
\hline
\end{tabular}

menderita pre eklampsi memiliki umur dengan resiko tinggi yaitu $<20$ tahun atau $>35$ tahun sementara ibu tidak rutin memeriksakan kehamilannya untuk mengontrol faktor-faktor resiko terjadinya pre eklampsi sehingga menyebabkan kejadian pre eklampsi pada ibu hamil.

c. Mengidentifikasi hubungan persalinan preterm dengan kejadian asfiksia neonatorum Hasil penelitian yang telah dilakukan di Ruang NICU RSUD Kota Mataram menunjukkan bahwa bayi asfiksia neonatorum pada ibu yang mengalami pre eklampsia adalah 39 (62,9\%) dibandingkan pada ibu yang tidak mengalami pre eclampsia adalah $23(37,1 \%)$. Jadi dapat disimpulkan bahwa, ibu yang mengalami pre eklampsia cenderung bayinya asfiksia neonatorum. 
Hasil uji analisa statistik dengan menggunakan uji chi square diperoleh hasil $\mathrm{p}$ value $=0,000(\mathrm{p}<$ $0,05)$. Hal ini menunjukkan bahwa terdapat hubungan yang signifikan antara kejadian pre eklampsia dengan Kejadian Asfiksia Neonatorum di Ruang Nicu RSUD Kota Mataram Tahun 2020. Pre eklampsia mengakibatkan tekanan darah yang tinggi menyebabkan berkurangnya kiriman darah ke plasenta. sudah pasti ini akan mengurangi suplai oksigen dan makanan bagi bayi. Akibatnya, perkembangan bayi menjadi lambat, dan terjadi hipoksia intrauterin, lebih fatal lagi, penyakit ini bisa menyebabkan lepasnya jaringan plasenta secara tiba-tiba dari uterus sebelum waktunya. Ketidakmampuan bayi setelah dilahirkan untuk bernapas normal karena gangguan pertukaran dan transport oksigen dari ibu ke janin sehingga terdapat gangguan ketersediaan oksigen dan pengeluaran karbondioksida. Efek hipoksia ini adalah asfiksia. Oleh karena itu dapat disimpulkan bahwa pre eklampsia dalam kehamilan menyebabkan resiko terjadinya asfiksia pada bayi baru lahir. (Indah \& Apriliana, 2016)

Bayi asfiksia neonatorum pada ibu yang mengalami pre ekalmpsia disebabkan karena pada ibu yang mengalami pre eklampsia. Pre eklampsi beresiko terhadap kelahiran bayi asfiksia karena pre eklampsi pada ibu hamil akan mempengaruhi suplay oksigen pada bayi, dan memicu terjadinya persalinan premature. Organ-organ tubuh bayi termasuk sistem pernafasan bayi belum sempurna, paru-paru bayi belum matang sehingga beresiko mengalami kegagalan dalam proses pernafasan secara spontan di luar rahim sehingga bayi mengalami asfiksia. Selain itu bayi prematur tidak menghasilkan surfaktan dalam jumlah yang memadai sehingga alveolus paru tidak dapat berkembang dengan baik yang menyebabkan terjadinya asfiksia neonatorum pada bayi. (Mundari, 2017)

Hal ini sesuai dengan penelitian deskriptif yang dilakukan oleh Raras (2011) menyebutkan bahwa pre eklampsia berat dapat menghasilkan keluaran perinatal meliputi Berat Bayi Lahir Rendah (37\%), pertumbuhan janin terhambat $(6,9 \%)$, kelahiran preterm $(28,3 \%)$, asfiksia neonatorum $(16,7 \%)$, dan kematian perinatal (93\%). (Raras, 2011)

Hal ini sejalan dengan penelitian yang dialkukan oleh Yuanita Syaiful (2016) dengan judul "Faktor Yang Berhubungan Dengan Kejadian Asfiksia Neonatorum Di RS Muhammadiyah Gresik (The Factors Causing Asphyxia Neonatorum in Gresik Muhammadiyah Hospital)" yang menyatakan bahwa 11 responden (46\%) lahir kurang bulan sehingga mengalami asfiksia neonatorum, 5 responden (21\%) lahir lebih bulan lebih lahir dengan asfiksia neonatorum. Hasil analisa statistik dengan Spearman's Rho menunjukkan bahwa signifikan dengan hasil hitung $\varrho=0,000$ artinya ada hubungan antara masa gestasi dengan kejadian asfiksia pada bayi baru lahir dengan nilai $r=0,805$ yang berarti ada hubungan yang sangat kuat. (Syaiful, 2016)

Gangguan yang terjadi pada bayi baru lahir dari ibu yang menderita pre eklamsia disebabkan oleh beberapa faktor diantaranya adalah umur ibu, paritas, usia kehamilan, dan berat badan lahir bayi. Asfiksia neonatorum bisa juga disebabkan oleh ibu yang melahirkan dengan resiko pada usia $<20$ tahun dan $>35$ tahun. Hasil penelitian yang dilakukan oleh Ekasari (2015) terdapat pengaruh yang bermakna antara usia kehamian $(\mathrm{p}=0,001)$ dan berat lahir bayi $(\mathrm{p}=0,001)$ terhadap asfiksia pada ibu dengan pre eklamsia berat. (Ekasari, 2015)

\section{SIMPULAN}

Berdasarkan hasil penelitian dan pembahasan di atas, maka dapat ditarik kesimpulan sebagai berikut: dari 124 bayi yang diteliti, bahwa bayi asfiksia neonatorum pada ibu yang mengalami pre eklampsia adalah 39 (62,9\%) dibandingkan pada ibu yang tidak preeklampsia adalah 23 (37,1\%). Dan bias disimpulkan ada korelasi kejadian pre eklampsia dengan kejadian asfiksia neonatorum di ruang NICU RSUD Kota Mataram Tahun 2020.

$$
\text { Jurna } 1 \text { Ke bida n a }
$$




\section{REFERENSI}

Achadi, E. L. (2019). Kematian Maternal dan Neonatal di Indonesia. Rakerkernas 2019, 1-47.

Fanny, F. (2015). Sectio Caesarea sebagai Faktor Risiko Kejadian Asfiksia Neonatorum. Jurnal Majority, 4(8), 57-62.

Indradewi, G. K., Sukamdi, \& Pitoyo, A. J. (2019). Determinan Kematian Bayi di Indonesia (Analisis Data SDKI 2017).

Kusmiyati \& Katiandagho, N. (2015). Faktor Faktor Yang Berhubungan Dengan Kejadian Asfiksia Neonatorum di RSUD Liun kendage Tahuna. Ilmiah Bidan, Volume 3,(2), 1-11.

Meliati, L. (2013). Analisis Faktor Faktor Yang Berhubungan Dengan Kejadian Persalinan Prematur Di RSUP NTB. Jurnal Kesehatan Prima, sI(2), 1298-1307.

Syaiful, Y. (2016). FAKTOR YANG BERHUBUNGAN DENGAN KEJADIAN ASFIKSIA NEONATORUM DI RS MUHAMMADIYAH GRESIK (The Factors Causing Asphyxia Neonatorum in Gresik Muhammadiyah Hospital). Journals of Ners Community, 7(1), 55-60. http://journal.unigres.ac.id/index.php/JNC/artic le/view/114

Prawirohardjo, S. 2013. Ilmu Kebidanan, Jakarta:
Raras, A. A., \& Cahyanti, R. D. (2011). Pengaruh Preeklamsia Berat Pada Kehamilan Terhadap Keluaran Maternal dan Perinatal di RSUP DR KARIADI SEMARANG TAHUN 2010 (Doctoral dissertation, Faculty of Medicine).

Ekasari, W. U. (2015). Pengaruh umur ibu, paritas, usia kehamilan, dan berat lahir bayi terhadap asfiksia bayi pada ibu pre eklamsia berat (Doctoral dissertation, UNS (Sebelas Maret University)).

Indah, S. N., \& Apriliana, E. (2016). Hubungan antara Preeklamsia dalam Kehamilan dengan Kejadian Asfiksia pada Bayi Baru Lahir. Jurnal Majority, 5(5), 55-60.

Mundari, R. (2017). HUBUNGAN KEJADIAN PREEKLAMPSIA DENGAN KEJADIAN ASFIKSIA NEONATORUM DI RSUD WATES KULON PROGO. Jurnal Kesehatan, 1(2), 17-17.

Rahmawati, S., \& Mawarti, R. (2014). Hubungan Preeklampsia dengan Kejadian Asfiksia Neonatorum di RSUD Panembahan Senopati Bantul Yogyakarta Tahun 2013 (Doctoral dissertation, STIKES 'Aisyiyah Yogyakarta).

Maryunani, A. (2010). Ilmu kesehatan anak dalam kebidanan. Jakarta: Trans Info Media. 